\title{
Colorectal cancer-derived microvesicles modulate differentiation of human monocytes to macrophages
}

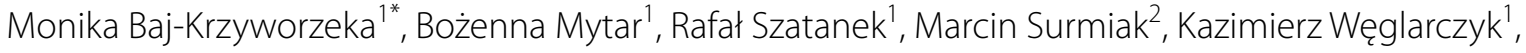 \\ Jarek Baran ${ }^{1}$ and Maciej Siedlar ${ }^{1}$
}

\begin{abstract}
Background: Tumour-derived microvesicles (TMVs) are important players in tumour progression, modulating biological activity of immune cells e.g. lymphocytes, monocytes and macrophages. This phenomenon is particularly interesting in the progression of colon cancer, as macrophages in this type of tumour are relevant for the recovery processes. In the present study, the role of colon cancer cell-derived microvesicles in monocyte differentiation and activity profile (polarization) was investigated.

Methods: Monocyte-derived macrophages (MDM) were differentiated in vitro in the presence of TMVs obtained from colon cancer: Caco-2, SW620, LoVo or SW480 cell lines and analysed according to their morphology and biological functions, as defined by cytokine secretion, reactive oxygen intermediate (ROI) production and cytotoxic activity against respective colon cancer cells.

Results: Monocytes differentiated with TMVs exhibited morphological and phenotypical characteristics of macrophages. An early contact (beginning with the first day of the in vitro culture) of monocytes with TMVs resulted in increased IL-10 secretion and only slightly elevated TNF release. Early, or prolonged contact resulted in low ROI production and low cytotoxicity against tumour cells. On the other hand, late contact of MDM with TMVs, stimulated MDM to significant TNF and IL-12 secretion, ROI production and enhanced cytotoxicity against tumour cells in vitro. In addition, differences in MDM response to TMVs from different cell lines were observed (according to cytokine secretion, ROI production and cytotoxicity against tumour cells in vitro). Biological activity, STATs phosphorylation and microRNA profiling of MDMs indicated differences in their polarization/activation status which may suggest mixed polarization type M1/M2 with the predominance of proinflammatory cells after late contact with TMVs.
\end{abstract}

Conclusions: Macrophage activity (polarization status) may be regulated by contact with not only tumour cells but also with TMVs. Their final polarization status depends on the contact time, and probably on the vesicle "cargo", as signified by the distinct impact of TMVs which enabled the switching of MDM maturation to regulatory macrophages.

Keywords: Tumour-derived microvesicles, Macrophages, Monocytes, Regulatory cells

\section{Background}

Colorectal cancer is the third most common cancer and the fourth most frequent cause of cancer deaths worldwide $[1,2]$. This type of tumour occurs generally after

\footnotetext{
*Correspondence: mibaj@cyf-kr.edu.pl

${ }^{1}$ Department of Clinical Immunology, Institute of Peadiatrics, Medical College, Jagiellonian University, 265 Wielicka str., 30-663 Cracow, Poland Full list of author information is available at the end of the article
}

the age of 50 and in most cases is sporadic, however, the occurrence of genetic or epigenetic causes along with the inflammatory microenvironment support colorectal cancer development [3]. The infiltrating leukocytes, mainly monocytes, which give rise to macrophages, are the hallmarks of this process [4]. The majority of macrophages infiltrating neoplastic tissue (TAM, tumour associated macrophages) have phenotype characteristics of M2 polarized cells, which are known to participate in 
each step of cancer progression including dissemination, seeding and metastasis formation [5]. The level of their infiltration is used as an independent prognostic factor in many tumour types [6]. However, it should be noted that in case of colorectal cancers, a strong macrophage infiltration does not necessarily correlate negatively with patients' survival $[4,7,8]$. This may be associated with proinflammatory TAMs, which play an antitumour role, leading to a favourable prognosis [9]. Different biological properties of macrophages could be associated with distinct factors (growth factors, cytokines etc.) in their microenvironment during the differentiation process [10]. The tumour microenvironment is a very complex system of cell to cell interplay complemented by cellular interactions with the extracellular environment. Tumour cells are essential players in these processes, however, other factors should be also taken under consideration. One of the most intriguing factors are ubiquitous extracellular vesicles (EVs). During tumour progression, monocytes in blood, as well as macrophages in the tumour bed, are exposed to EVs released by nearby cells $[11,12]$ to body fluids $[13$, 14]. EVs are defined as membrane fragments of various shapes released by cells during their lifespan. Using the size and origin criteria, EVs are classified into two groups: exosomes, which are smaller (30-100 nm), more homogeneous in size and released by the endosomal compartment, and ectosomes, also known as microvesicles (MVs) [15], which are larger $(0.1-1 \mu \mathrm{m})$ [16] and mainly originated from plasma membranes. EVs are also released by tumour cells, thus, impacting the activity of blood monocytes and TAM in tumour bed [17]. Based on their cargo (proteins, growth factors, mRNA and microRNAs) EV are regarded as "messengers" [12-15], which may affect biological activity of macrophages. miRNAs deserve special attention as they may regulate all differentiation steps and change the activation status of macrophages [18]. In the present study, we asked whether TMVs released by colon cancer cell lines (with different growth potential) may influence monocyte differentiation, thus, affecting their activity/polarization status. In another words, we asked, if TMVs, as tumour "go-between" present in body fluids/ tumour environment, may direct/educate monocytes during their differentiation. Our results indicate an important role of TMVs in this process and suggest that TMVs origin and the time of their "first contact" with monocytes/ macrophages are crucial for their ultimate activity and function.

\section{Methods}

\section{Isolation of monocytes}

Human peripheral blood mononuclear cells (PBMCs) were isolated from EDTA-blood of healthy donors by the Ficoll/Isopaque (Pharmacia, Uppsala, Sweden) density gradient centrifugation. Monocytes were separated from PBMCs by counter-flow centrifugal elutriation with the JE-6B elutriation system equipped with a $5 \mathrm{ml}$ Sanderson separation chamber (Beckman-Coulter, Palo Alto, CA), as previously described [19]. Monocytes were suspended in RPMI 1640 culture medium (PAA Laboratories, Pasching, Germany) with gentamycin (Sigma, St. Louis, MO) $(25 \mu \mathrm{g} / \mathrm{ml})$. Purity of monocytes was over $95 \%$, as judged by staining with anti-CD14 mAb (BD Biosciences Pharmingen, San Diego, CA) and flow cytometry analysis (FACSCanto BD Biosciences Immunocytometry Systems, San Jose, CA). The study was approved by the local Jagiellonian University Ethical Committee (No. $\mathrm{KBET} / 160 / \mathrm{b} / 2011)$.

\section{Isolation of TMVs}

TMVs were obtained from the following human colon cancer cell lines: Caco-2, SW480, SW620 and LoVo as previously described [20]. The cell lines were a generous gift from prof. Caroline Dive (Paterson Institute for Cancer Research, The University of Manchester). Cell lines differed in malignancy potential as Caco-2 was described as poorly aggressive, SW480-with low metastatic ability, SW620-high metastatic ability and LoVo-undifferentiated. Cells were cultured by bi-weekly passages in RPMI 1640 (Caco-2 and LoVo) or DMEM (SW480 and SW620) (PAA) with $5 \%$ FBS (foetal bovine serum, Biowest, Nuaille, France) centrifuged before the use at 50,000 $\times g$ for bovine-derived MVs depletion. Cell lines were regularly tested for Mycoplasma sp. contamination by using PCR-ELISA kit according to the manufacturer's protocol (Roche, Mannheim, Germany). Supernatants from wellgrown cell cultures were collected, centrifuged at $2000 \times g$ for $20 \mathrm{~min}$ to remove cell debris and then centrifuged again at 50,000 $\times g($ RC28S, Sorvall, Newton, CT) for $1 \mathrm{~h}$ at $4{ }^{\circ} \mathrm{C}$. Pellets were washed twice in PBS to remove FBS and finally resuspended in serum-free medium. Quantification of TMVs proteins was evaluated by the Bradford method (BioRad, Hercules, CA). TMVs were tested for endotoxin contamination by the Limulus test according to the manufacturer's instruction (Charles River Laboratories, Inc., Wilmington, MA) and stored at $-20{ }^{\circ} \mathrm{C}$ until use. As an additional control for some experiments MVs from non-malignant urothelial cells HCV-29 were used. To simplify, TMVs were named according to their cell line origin e.g. TMVs released from Caco-2 as TMV$\mathrm{Caco}_{2}$, from LoVo-TMV $\mathrm{LoV}_{\mathrm{L}}$, from SW480-TMV $\mathrm{SW}_{480}$, from SW620 as TMV $\mathrm{SW}_{620}$ and from HCV-29 as $\mathrm{MV}_{\mathrm{HCV}}$.

\section{Differentiation of monocytes to monocyte-derived macrophages (MDM)}

Blood monocytes were cultured for 7 days in 24-well low attachment plates (Corning Incorporated, Corning, NY) 
at the density of $1 \times 10^{6} /$ well at $37^{\circ} \mathrm{C}, 5 \% \mathrm{CO}_{2}$ in humidified atmosphere. In the preliminary experiments, RPMI 1640 medium supplemented with FBS (low in endotoxin and MV-depleted) was established as adequate for differentiation of human monocytes to MDM. Also, the dose of TMVs $(3 \mu \mathrm{g} / \mathrm{ml})$ that had no impact on the viability of MDM (see below) was established during the preliminary experiments. TMVs $(3 \mu \mathrm{g} / \mathrm{ml})$ were added to the monocyte culture in three different combinations: (i) at day 0 (abbreviated as MDM + TMVOd), (ii) at days 0,3 , 6 (MDM + TMV036d), (iii) at day 6 (MDM + TMV6d) (Fig. 1). After 3 days of culture, half of the medium was removed and replaced with freshly prepared one. Our previous results indicated that TMVs supplemented at day 0 were completely engulfed after $24 \mathrm{~h}$, so the risk to remove them was unlikely [20]. Monocytes cultured alone (without TMVs) were used as a control (equivalent to M0 macrophages) [21] and defined as control MDM. In parallel, MDM were differentiated in the presence of GM-CSF (1000 U/ml, Immunotools GmbH, Friesoythe, Germany) or M-CSF (10 ng/ml, Peprotech, Princeton, $\mathrm{NY}$ ) which have been described to induce an M1 and M2 like phenotype, respectively [21]. As an additional control $\mathrm{MV}_{\mathrm{HCV}}$ and fluorescent beads [0.4 $\mu \mathrm{m}$ Fluoresbrite Yellow Green (YG) carboxylate microspheres, Polysciences, Warrington, USA] were used, to check the impact of normal MVs and the engulfment process on
MDM differentiation. After 7 day culture, cell viability was determined by Annexin V (BD Pharmingen) binding and TO-PRO-3 (Invitrogen, Waltham, MA) staining; only cells with viability above $95 \%$ were used for further testing.

\section{Morphology and phenotype of MDM}

The morphology of macrophages was investigated daily by phase contrast microscopy (600× magnification) Olympus IX70 (Olympus Corp. PA). MDM morphology was assessed using cytospin slides stained for 3 min with the Wright's dye (Merck, Darmstadt, Germany) at the last day of culture by light microscopy (Olympus BX51). Phenotype analysis was performed at day 7 using flow cytometry. The following monoclonal antibodies (mAbs) were used: APC-labelled anti-CD14, FITC-labelled anti-CD33, -CD80, -CD15, PE-labelled anti-CD1a, -CD206, -CD86, -CD11b, PerCP-labelled anti-HLA-DR, PerCP-Cy5.5labelled anti-CD163, all from BD Pharmingen. Antibodies from R\&D System: FITC-labelled anti-CD115 (MCSF-R), PE-labelled anti-CD36. For intracellular staining (CD68 FITC) MDM were fixed with Cytofix and permeabilised with PermWash buffers, both from BD Pharmingen. CD68 staining was done using mAb from Dako Cytomation (Glostrup, Denmark). Additionally, kinetics of CD206 expression was examined on a daily basis using flow cytometry. All antibodies were used in saturating

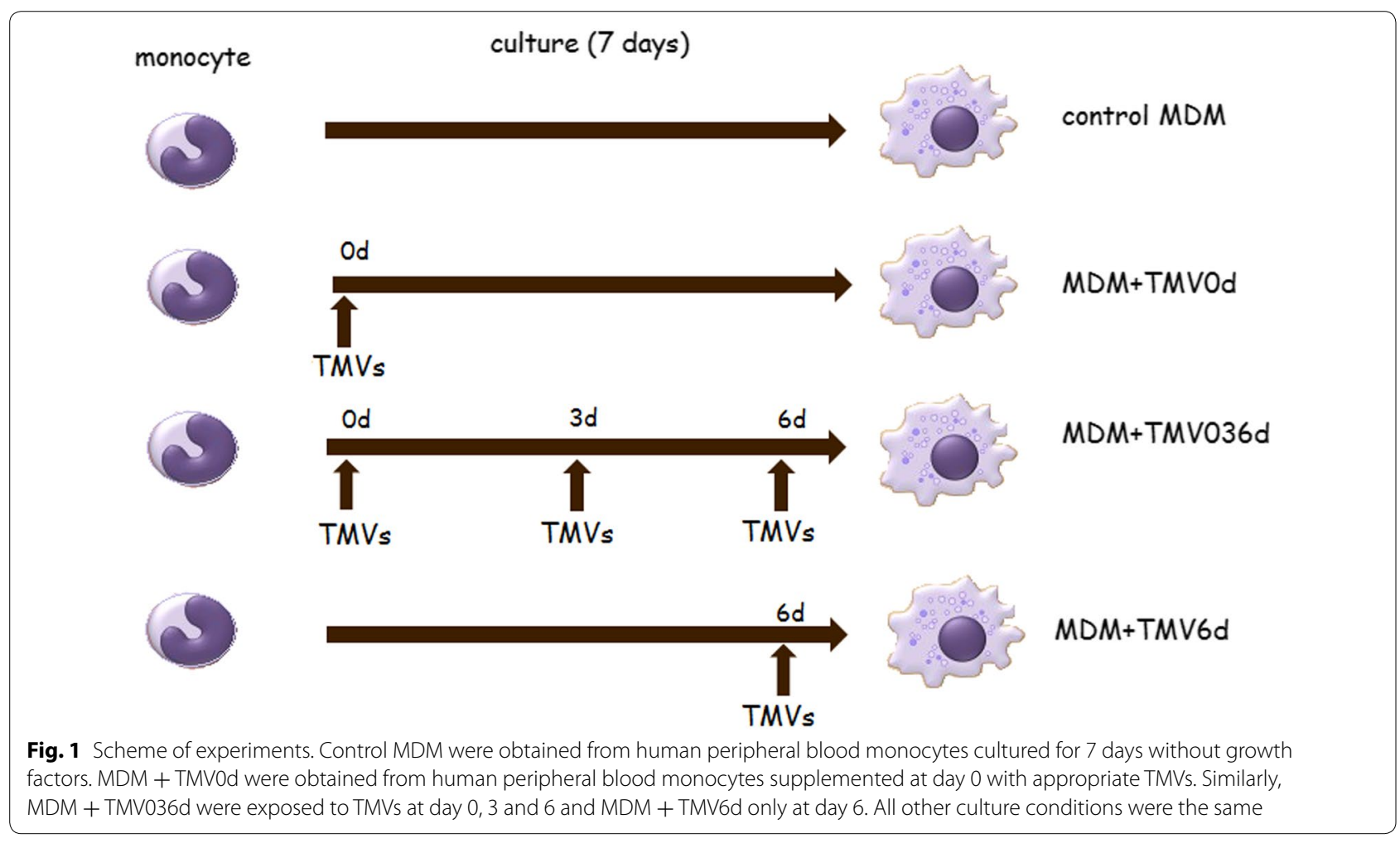


concentrations with appropriate isotype-matched controls. MDM were incubated with mAbs for $30 \mathrm{~min}$ at $4{ }^{\circ} \mathrm{C}$, washed and then analysed in FACSCanto flow cytometer.

\section{Cytokine secretion}

Supernatants obtained on day 7 of the MDM culture were collected and the concentration of TNF, IL-10 and IL-12 was measured by the following matched mAbs pairs for ELISA (BD Pharmingen): for TNF-MAb1 (capture) and MAb11 (detection), for IL-10-JES3-9d7 (capture) and JES-12G8 (detection) and for IL-12p40/ p70-C8.3 (capture) and C8.6 (detection). Recombinant human cytokines (all from BD Pharmingen) were used as standards. Tests were performed according to the manufacturer's protocol and results were obtained using the ELISA reader (BioTek Instruments, Vinooski, VT) at 492 vs $630 \mathrm{~nm}$ wavelength. Detection level for TNF was $20 \mathrm{pg} / \mathrm{ml}$, and $10 \mathrm{pg} / \mathrm{ml}$ for IL-10, IL-12p40/p70.

\section{microRNA (miR) expression}

MDM differentiated in the presence of TMVs $\left(\mathrm{TMV}_{\mathrm{SW} 480}, \mathrm{TMV}_{\mathrm{SW} 620}, \mathrm{TMV}_{\mathrm{LoVo}}\right.$ and $\left.\mathrm{TMV}_{\mathrm{Caco} 2}\right)$ were tested for miR expression profile. The total RNA was extracted from MDM, MDM + TMVs (after 7 days of culture) and TMVs alone with mirVana ${ }^{\mathrm{TM}}$ miRNA Isolation Kit (Ambion, Life Technologies, Austin, TX) according to the manufacturer's protocol. The first strand cDNA was obtained from the total RNA (400 ng) samples with Megaplex $^{\mathrm{TM}}$ RT Primers (pool A and B, Applied Biosystems, Foster City, CA). TaqMan Array Micro RNA Card Set v3.0 were used to detect expression of human miRs in preliminary studies. Real-time PCR was performed using the 7900HT System (Applied Biosystems). For miRs, which major differences in expression were detected in preliminary experiments (miR-9,-21,-155,-378,-511) individual real-time PCRs (TaqMan Gene Expression Assays, Applied Biosystems) were performed. All experiments were performed three times and the PCR reactions were performed in triplicates using the 7300 Real-Time PCR System (Applied Biosystems). Reverse transcription was performed as described above (Megaplex RT primers pool A were used for miR-9,-21,-155,-511 and U6 as a control, Megaplex RT primers pool B were used for miR378 and U6). The fluorescent signals generated during the informative log-linear phase were used to calculate the relative amount of miR. U6 was used as a control for each PCR run and the miR expression was calculated as a fold difference from that of control MDM normalized by U6 results $\left(2^{-\Delta \Delta C T}\right)$.

\section{Determination of ROI production by flow cytometry}

The intracellular production of ROI was measured by flow cytometry using oxidation-sensitive fluorescent probe hydroethidine (HE, Sigma). After 7 days, MDM expanded alone or in the presence of TMVs (added in the described regimen) were preincubated with $10 \mu \mathrm{M}$ $\mathrm{HE}$ for $30 \mathrm{~min}$ and stimulated with phorbol 12-myristate 13-acetate ( $4 \mu \mathrm{M}$ PMA, Sigma) for $10 \mathrm{~min}$, after which cells were washed and analysed immediately with FACSCanto flow cytometer.

\section{Western blotting}

To assess the master regulators in signalling processes that lead towards M1 (STAT1, STAT5) or M2 (STAT3, STAT6) differentiation Western blotting technique was employed. Monocytes were stimulated with TMVs for $30^{\prime}, 2 \mathrm{~h}, 4 \mathrm{~h}$ and $7 \mathrm{~h}$ at day 0 or day 6 . After stimulation cells were lysed in M-PER lysing buffer (Pierce, Rockford, IL) containing protease inhibitor cocktail (Roche). As a control unstimulated monocytes/MDM were used. The concentration of samples was measured using the Bradford kit (Bio-Rad) as per manufacturer's instruction. $20 \mu \mathrm{g}$ of isolated protein was mixed with NuPAGE LDS Sample Buffer $(4 \times)$ (Life Technologies, Carlsbad, CA) and NuPAGE Sample Reducing Agent $(10 \times)$ (Life Technologies). Samples were heated $\left(70{ }^{\circ} \mathrm{C}, 10 \mathrm{~min}\right)$ and electrophoresed in $12 \%$ polyacrylamide gel containing SDS. Next, electrophoresed samples were transferred onto the polyvinylidene fluoride membrane (Bio-Rad). Then, after blocking for $1 \mathrm{~h}$ at room temperature in Tris buffered saline (TBS) with $0.1 \%$ Tween-20 (Sigma, St. Louis, $\mathrm{MO}$ ) and $1 \%$ bovine serum albumin (BSA, Sigma) the membranes were incubated overnight at $4{ }^{\circ} \mathrm{C}$ with rabbit polyclonal antibodies: anti-phopspho-STAT1 (Tyr701), anti-phospho-STAT3 (Tyr705), anti-phospho-STAT5 (Tyr694), anti-total STAT1, anti-total STAT3 and antitotal STAT5 (all antibodies were purchased from Cell Signaling, Danvers, MA) diluted 1:1000. After incubation, membranes were washed in TBS supplemented with BSA and Tween-20 and incubated for $1 \mathrm{~h}$ at room temperature with secondary goat anti-rabbit antibody (dilution 1:2500) conjugated with horseradish peroxidase (Cell Signaling). The protein bands were visualized with the SuperSignal West Pico Chemiluminescence Substrate kit (Pierce) according to the manufacturer's protocol and analysed with KODAK GEL LOGIC 1500 Digital Imaging System (KODAK, Rochester, NY).

\section{Cytotoxicity assay}

MDM cytotoxicity against tumour cells was tested, as described previously [21]. Briefly, after 7 day culture, MDM $\left(5 \times 10^{4} /\right.$ well $)$ grown alone or with TMVs were cocultured with the appropriate tumour cells (autologous) $\left(2 \times 10^{4} /\right.$ well $)$ for $48 \mathrm{~h}$, after which the culture medium was removed and $100 \mu \mathrm{l}$ of 1, 3-[4,5-dimetylthiazol-2-yl]-2,5-diphenyltetrazolium bromide (MTT, 
$2 \mathrm{mg} / \mathrm{ml}$, Sigma) dye solution was added for $4 \mathrm{~h}$. The experiment was repeated 5 times in triplicates. Formed formazan was extracted with isopropyl alcohol (Fluka Chemie AG, Buchs, Switzerland) containing 0,04 N $\mathrm{HCl}$ and its content was measured spectrophotometrically (absorbance at 570 and $630 \mathrm{~nm}$ ). The percentage of cytotoxicity was calculated according to the formula described previously [22].

\section{Statistical analysis}

Statistical analysis was performed by nonparametric Mann-Whitney test. Differences were considered significant at $\mathrm{p}<0.05$.

\section{Results}

Monocytes in the presence of TMVs differentiate to macrophages

The presence of TMVs during the culture significantly changes morphology of MDM (Fig. 2). It was observed that MDM form clusters after exposure to TMVs. When cultures were monitored daily, the "spreading out" of MDM from the clusters was observed at day 5 (Fig. 2). Control MDM as well as MDM after beads engulfment did not form clusters. Control MDM after 7 day culture exhibited heterogeneous shapes including elongated and round cells (Fig. 2a). MDM generated in the presence of $\mathrm{TMV}_{\mathrm{SW} 620}$ from day $0\left(\mathrm{MDM}+\mathrm{TMV}_{\mathrm{SW} 620} \mathrm{Od}\right)$ were heterogeneous in shape (Fig. 2b). Accountable "fried egg"-shaped cells next to clusters were observed when $\mathrm{TMV}_{\mathrm{SW} 620}$ were supplemented at the final differentiation stage $\left(\mathrm{MDM}+\mathrm{TMV}_{\mathrm{SW620}} 6 \mathrm{~d}\right.$, Fig. 2b). $\mathrm{MDM}+\mathrm{TMV}_{\mathrm{Caco} 2}$ Od were predominantly elongated (Fig. 2c). When $\mathrm{TMV}_{\mathrm{Caco2}}$ were supplemented at day 6 , MDM formed cluster-like structures (Fig. 2c). Similar pattern was observed for $\mathrm{TMV}_{\mathrm{SW} 480}$ (Fig. 2e), with "fried egg"-shaped cells more frequent at day 6 . In the case of $\mathrm{TMV}_{\mathrm{LoVo}}$, spindle-like cells were rare, while most of them resembled adherent macrophages (Fig. 2d), with "fried egg"-shaped morphology. In general, spindlelike MDM, which resembled cells cultured with M-CSF (Fig. 2h) were more frequent when TMVs were added at 0d. In contrast, MDM supplemented with TMV at day 6, looked similar to those differentiated with GM-CSF (Fig. 2h). MDM cultured with beads did not form cluster structures at all, and looked almost the same during the whole culture period (Fig. 2g). MDM supplemented with $\mathrm{MV}_{\mathrm{HCV}}$ were similar despite the time of the contact with $\mathrm{MV}_{\mathrm{HCV}}$ (Fig. 2f).

MDM differentiated in the presence of TMVs were usually bigger with higher granularity (as judged by flow cytometry and light microscopy) (Fig. 3a, b).

Control MDM as well as MDM + TMVs expressed CD14 molecules in the absence of the typical markers of dendritic cells (CD1a) and granulocytes (CD15) (data not shown). However, MFI of CD14 was significantly higher in MDM + TMV6d $(28,117 \pm 9906)$ in comparison to other groups $(11,804 \pm 6422$ for control MDM and $12,096 \pm 4991$ for MDM + TMV0d). All MDM expressed macrophage-lineage marker CD68 (more than $90 \%$ ). Moreover, MDM were positive for $\mathrm{CD} 11 \mathrm{~b}$ and $\mathrm{CD} 33$ (70 and $33 \%$, respectively). Table 1 presents expression of selected markers on MDM cultured alone or with TMVs. Differences in marker expression were observed in the case of CD206, CD36, CD80, CD86, and CD163 after contact with particular TMVs and their significance was denoted with an asterisk ("p $<0.05$, Table 1 ). Interestingly, we observed a dynamic increase in CD206 positive cells during the first days after contact with TMVs (Fig. 4). The annexin V binding (less than $3 \%$ of cells), and the TO-PRO-3 staining (below $2 \%$ ) were low (not shown). As an additional control, MDM cultured with $\mathrm{MV}_{\mathrm{HCV}}$ or fluorescent beads were used. No differences in the expression level of tested markers (as above) were observed between control MDM and $\mathrm{MDM}+\mathrm{MV}_{\mathrm{HCV}}$ or MDM + beads (data not shown).

\section{MDM + TMVOd and MDM + TMV6d differ in microRNA expression}

Differences in expression of a number of miRs were observed including miR-9,-10a,-125a,-130a,-146a,-146b,$15,-155,-21,-222,-223,-27 \mathrm{a},-328,-378,-511,-1254$. The most important miRs for differentiation and polarization process were analysed in subsequent experiments with TaqMan probes. We confirmed that MDM + TMV6d expressed more miR-155 than MDM + TMV0d (Fig. 5a). Upregulation of miR-378 was detected only in $\mathrm{MDM}+\mathrm{TMV}_{\mathrm{LoVo}} 6 \mathrm{~d}$ and $\mathrm{MDM}+\mathrm{TMV}_{\mathrm{SW} 480} 6 \mathrm{~d}$ in comparison to MDM + TMVOd (Fig. 5b). These two miRs are described to be associated with M1 polarization type. In parallel, we observed upregulation of miR-9 in all MDM + TMVs in comparison to control MDM, however expression of miR-9 in MDM + TMV0d was much higher than in MDM + TMV6d. Significant differences were observed in the presence of $\mathrm{TMV}_{\mathrm{Caco} 2}$ (Fig. 5c). A similar trend was observed in miR-21 expression (higher in MDM + TMV0d than in MDM + TMV6d, Fig. 5d). miR-9 and miR-21 expression may suggest M2-like polarization. Expression of miR-511 was significantly higher in MDM + TMV0d than in MDM + TMV6d which corroborates with the surface expression of CD206 (Fig. 5e).

\section{TMVs carry microRNA involved in macrophage differentiation}

In parallel to miRs analysis in MDM, miRs expression in TMVs was determined, however, only miRs detected at CT below 31 were analysed (set arbitrarily, average 


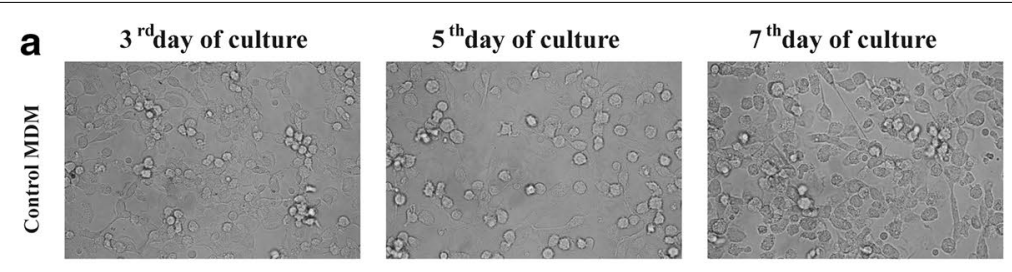

TMVs/MVs/beads added at:
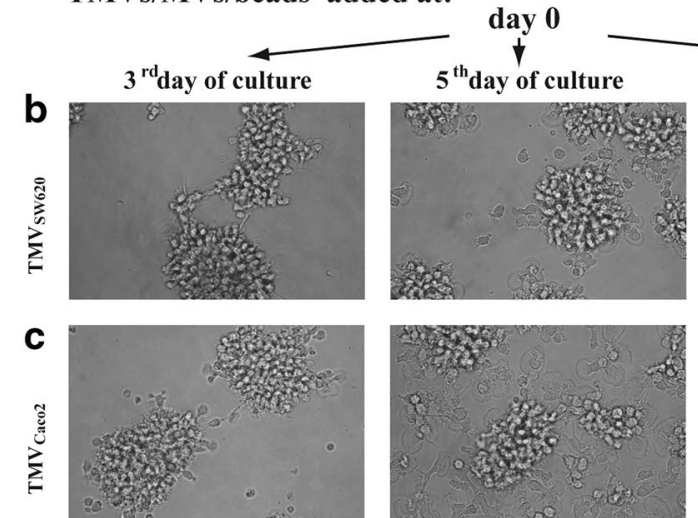

$7^{\text {th }}$ day of culture
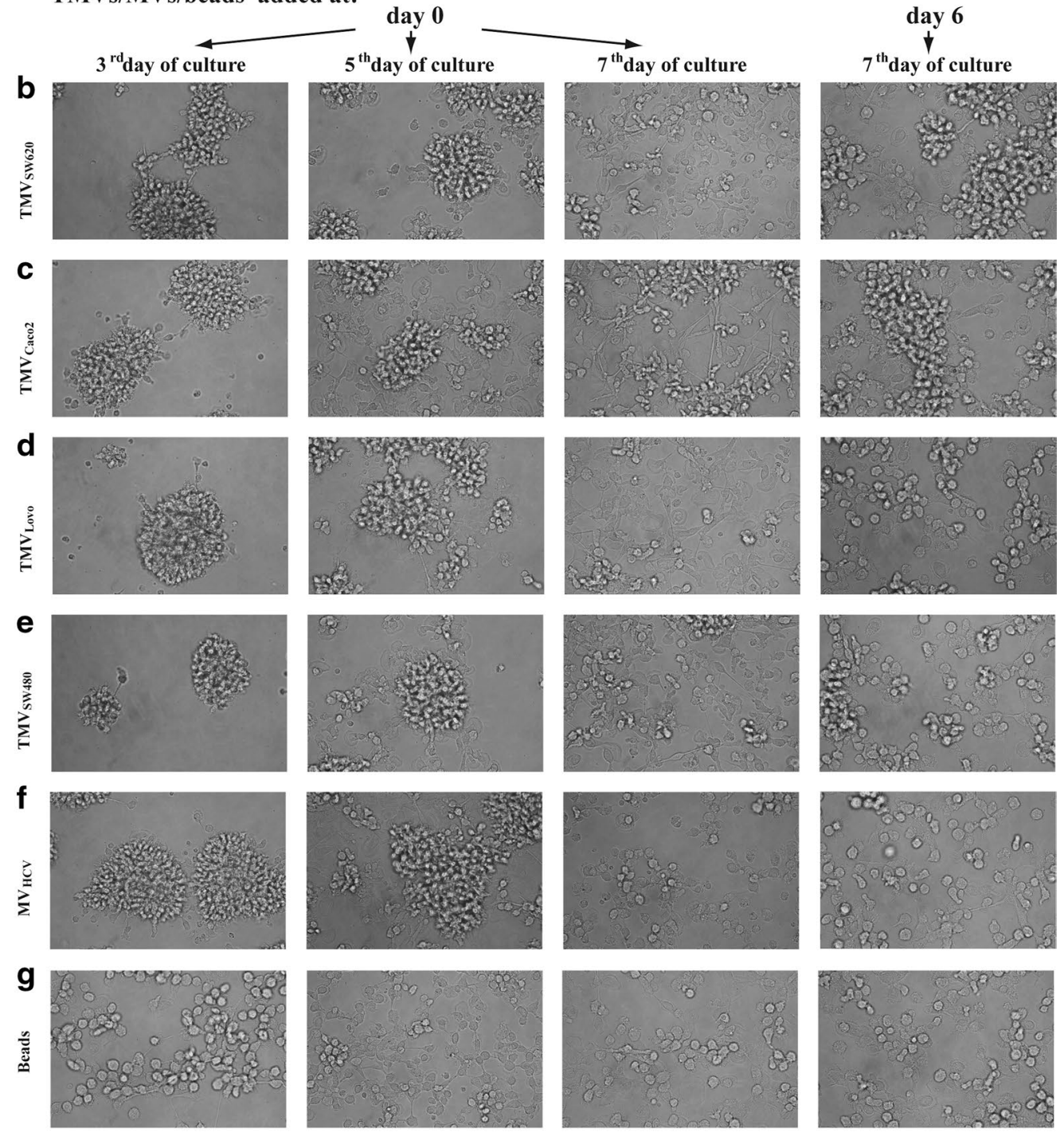

GM-CSF
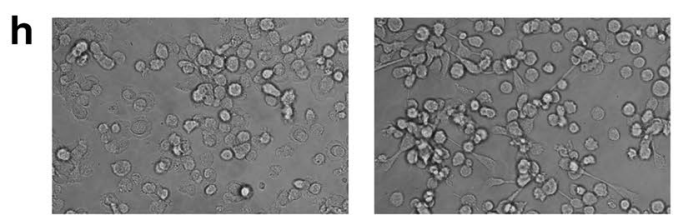

Fig. 2 Morphology of MDM (at day 3, 5 and 7) differentiated in the presence of medium alone (a) or TMVs: TMV SW620 $_{\text {(b), }}\left(\operatorname{TMV}_{\text {Caco2 }}(\mathbf{c}), \operatorname{TMV}_{\text {LoVo }}(\mathbf{d})\right.$, $\operatorname{TMV}_{\mathrm{SW} 480}(\mathbf{e}), \mathrm{MV}_{\mathrm{HCV}}(\mathbf{f})$, beads $(\mathbf{g})$ and growth factors $(\mathbf{h})$. One representative experiment out of ten is presented 


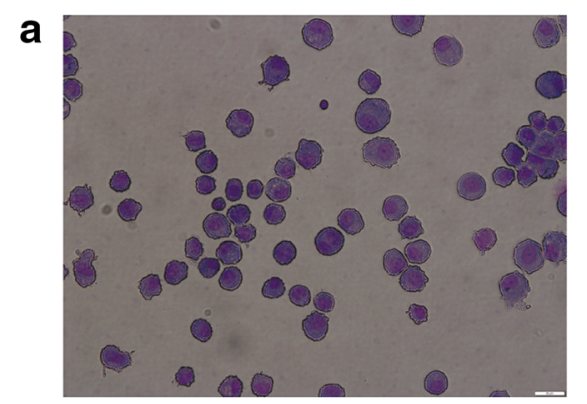

b

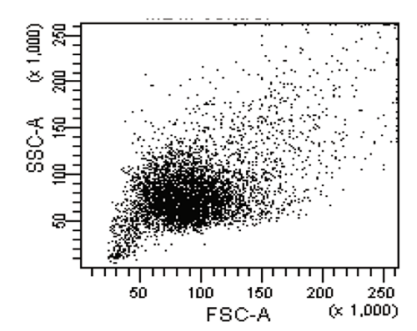

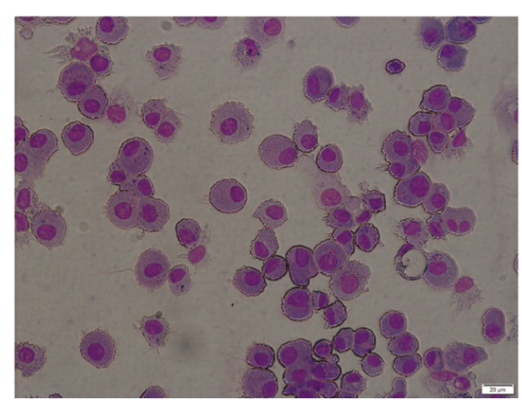

MDM+TMVOd

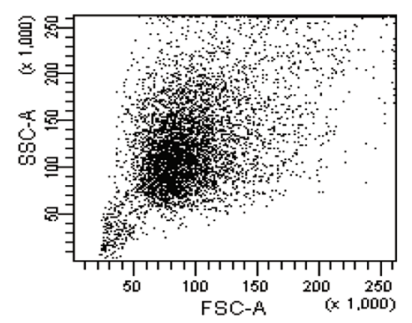

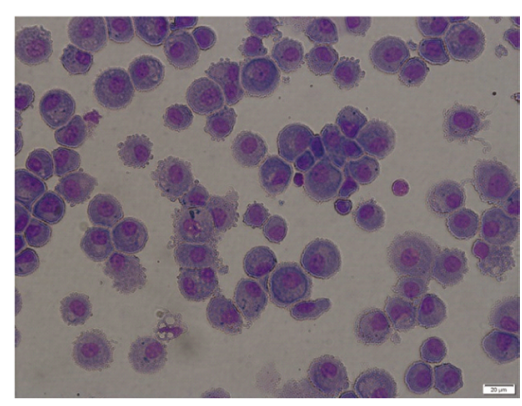

MDM+TMV6d

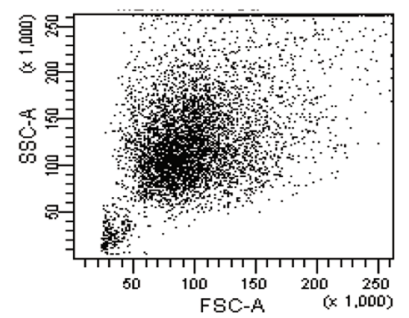

Fig. 3 MDM morphology analysed by cytospin slides after the Wright's staining (a) and flow cytometry FSC/SSC dot plot (b) of MDM differentiated in the presence of TMVs. Left panel-control, middle panel-MDM + TMV0d, right panel-MDM + TMV6d. (bar-50 $\mu m$ ). One representative example out of ten is presented

$\mathrm{CT}$ presented in brackets). The $\mathrm{TMV}_{\mathrm{Caco} 2}$ carried miR: -106a (27, 92), -146b (30, 31), -155 (27, 82), -223 (30, $15)$, and $-378(25,31), \mathrm{TMV}_{\mathrm{SW} 480}-\mathrm{miR}-106 \mathrm{a}(24,88)$, $-106 \mathrm{~b}(29,29),-146 \mathrm{a}(25,83),-21(28,16),-222(26$, $12),-223(27,62),-26 \mathrm{a}(28,02),-378(29,23)$ and -9 $(30,77), \mathrm{TMV}_{\text {SW620 }}-106 \mathrm{a}(24,59),-146 \mathrm{a}(30,06),-21$ $(30,28),-222(25,93),-223(29,13), \mathrm{TMV}_{\mathrm{LoVo}}-\mathrm{miR}-$ 106a (30, 76), -222 (29, 74), -328 (28, 70). miR-511 was not detected. Data are presented as a heat map (Fig. 5f).

\section{TMVs induce secretion of cytokines by MDM}

Secretion of cytokines by MDM was tested after 7 days of culture with/without TMVs (Fig. 6). In general, MDM + TMV6d secreted significantly more TNF $(850 \pm 303,839 \pm 199,1781 \pm 74,1355 \pm 559 \mathrm{pg} / \mathrm{ml}$ for $\mathrm{TMV}_{\mathrm{SW620}}, \mathrm{TMV}_{\mathrm{Caco} 2}, \mathrm{TMV}_{\mathrm{LoVo}}$ and $\mathrm{TMV}_{\mathrm{SW} 480}$, respectively) than MDM + TMVOd (TMVs in order as above: $311 \pm 62,190 \pm 114,399 \pm 119,49 \pm 24 \mathrm{pg} /$ $\mathrm{ml})$ and control MDM $(43 \pm 13 \mathrm{pg} / \mathrm{ml})$. Also secretion of IL-12 by MDM + TMV6d was elevated, except for $\mathrm{MDM}+\mathrm{TMV}_{\mathrm{SW620}}(340 \pm 199,863 \pm 280,741 \pm 457 \mathrm{pg} /$ $\mathrm{ml}$ for $\mathrm{TMV}_{\mathrm{Caco} 2}, \mathrm{TMV}_{\mathrm{LoVo}}$ and $\mathrm{TMV}_{\mathrm{SW} 480}$ respectively) in comparison to MDM + TMVOd (TMVs in order as above: $185 \pm 68,43 \pm 24,177 \pm 151 \mathrm{pg} / \mathrm{ml}$ ) and control MDM $(26 \pm 20 \mathrm{pg} / \mathrm{ml})$. Interestingly, secretion of TNF and IL-12 was the lowest in MDM + TMV036d (except for $\left.\mathrm{TMV}_{\mathrm{SW} 480}\right)$. In the case of MDM + TMV0d, lower TNF secretion (see above) was accompanied by the increased secretion of IL-10 (558 $\pm 258,491 \pm 184$,
$564 \pm 181,96 \pm 57 \mathrm{pg} / \mathrm{ml}$ for $\mathrm{TMV}_{\mathrm{SW620}}, \mathrm{TMV}_{\mathrm{Caco} 2}$, $\mathrm{TMV}_{\mathrm{LoV}}$ and $\mathrm{TMV}_{\mathrm{SW} 480}$, respectively) whereas elevated TNF (see above) and lower IL-10 levels (162 \pm 65 , $54 \pm 32,476 \pm 217,33 \pm 23 \mathrm{pg} / \mathrm{ml}$, for $\mathrm{TMV}_{\text {SW620 }}$ $\mathrm{TMV}_{\text {Caco2}}$, $\mathrm{TMV}_{\text {LoVo }}$ and $\mathrm{TMV}_{\mathrm{SW} 480}$, respectively) were observed in MDM + TMV6d. MV $_{\mathrm{HCV}}$ induced cytokines comparable with control MDM. Fluorescent beads did not induce TNF at all, while IL-10 and IL-12 secretion was similar to control MDM (data not shown).

\section{MDM + TMV6d produce high amounts of ROI}

MDM generated in the presence of TMVs produced ROI after PMA stimulation, however, the observed differences depended on the applied TMVs scheme. Significant increase of ROI production (mainly $\mathrm{O}_{2}{ }^{-}$) was observed only in MDM + TMV6d $(22+9,33 \pm 14$ and $37 \pm 12 \%$ of cells for $\mathrm{TMV}_{\mathrm{SW620}}, \mathrm{TMV}_{\mathrm{LoV}}$ and $\mathrm{TMV}_{\mathrm{SW} 480}$ respectively) in comparison to the control MDM and MDM + TMV0d (13 \pm 7$)$. A similar profile of ROI production was observed in three of the four tested TMVs $\left(\mathrm{TMV}_{\mathrm{SW} 480}, \mathrm{TMV}_{\mathrm{SW620}}\right.$, and $\left.\mathrm{TMV}_{\mathrm{LoVo}}\right) . \mathrm{TMV}_{\mathrm{Caco} 2}$ did not induce ROI production by MDM (Fig. 7).

\section{TMVs induce phosporylation of STAT1 and STAT3}

To assess the polarization of MDM stimulated with TMVs, Western blot technique was employed to analyze STAT-1, 3, 5 and 6. Phosphorylation of STAT1, 3, 5 and 6 was tested during the time interval of $30^{\prime}-7 \mathrm{~h}$. A weak phosphorylation signal for STAT1 in MDM Od 


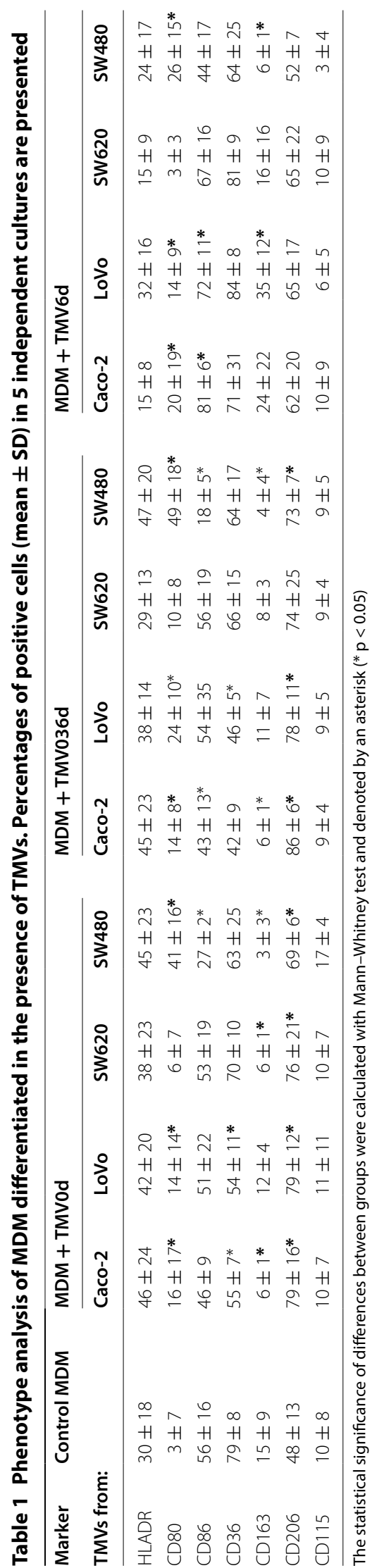




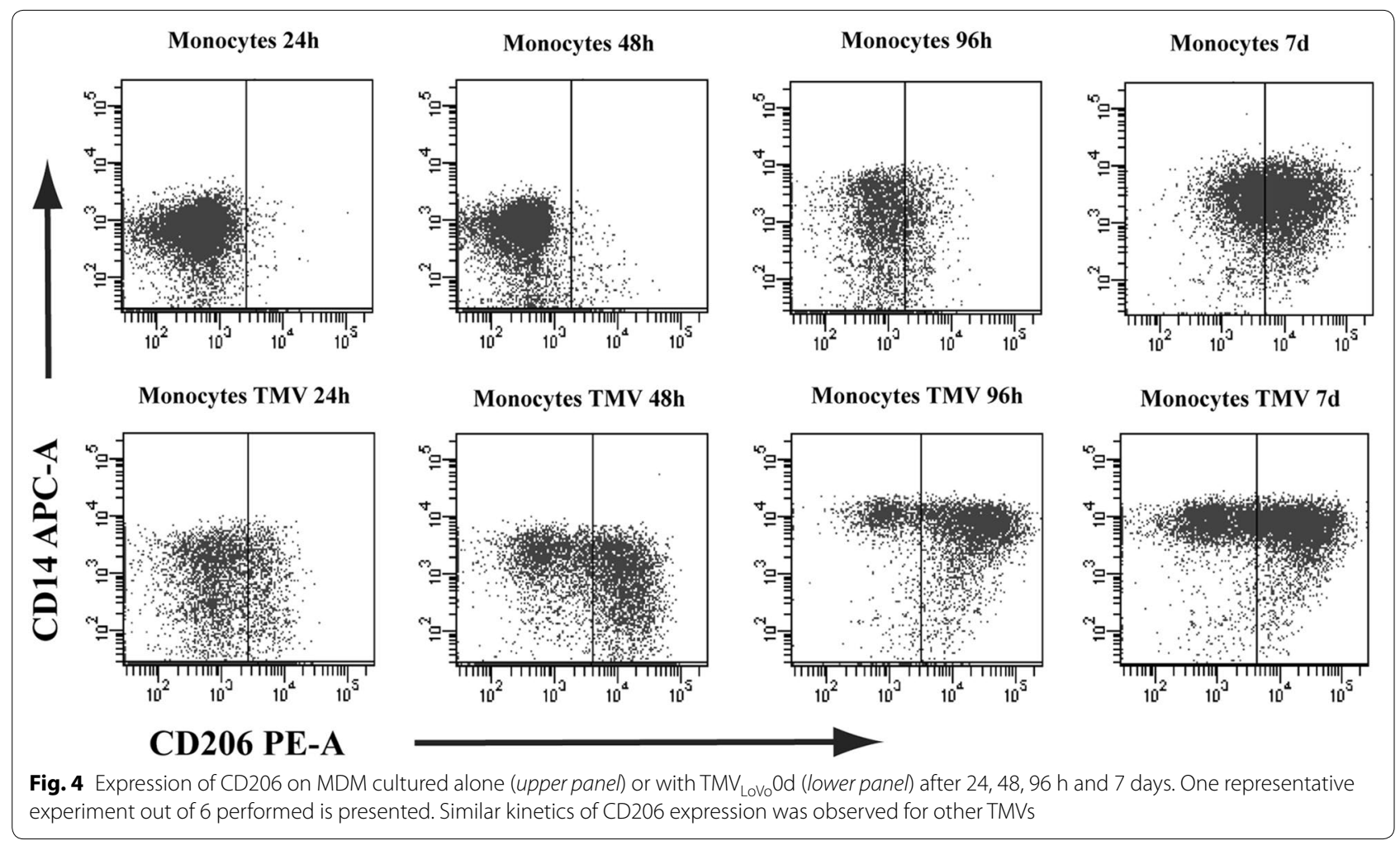

and $6 \mathrm{~d}$ stimulated with $\mathrm{TMV}_{\text {Lovo }}$ or $\mathrm{TMV}_{\mathrm{SW} 480}$ (Fig. 8a, c) for $7 \mathrm{~h}$ was detected. No phosphorylation of STAT1 was observed after $\mathrm{TMV}_{\mathrm{Caco} 2}$ and $\mathrm{TMV}_{\mathrm{SW620}}$ (Fig. 8b, d) stimulation. STAT3 was phosphorylated on tyrosine (but not serine) after stimulation (7 h) with any type of TMVs regardless of the time of contact (MDM 0d, MDM6d). STAT5 was phosporylated quickly ( $30^{\prime}$ stimulation) in all samples (including control MDM), while phosphorylation of STAT 6 was not detected (not shown). Data are presented as a representative (out of two perfomed) Western blot (Fig. 8).

\section{TMVs change cytotoxic/cytostatic activity of MDM}

Based on the obtained data, the cytotoxicity of control MDM in vitro against four tested colon cancer cell lines was app. $50 \%$. In general, MDM + TMV6d were more cytotoxic against tumour cells $(86 \pm 31,61 \pm 26,80 \pm 17$, $84 \pm 12 \%$ of cells for $\mathrm{TMV}_{\mathrm{SW620}}, \mathrm{TMV}_{\mathrm{Caco} 2}, \mathrm{TMV}_{\mathrm{LoV}}$, $\mathrm{TMV}_{\mathrm{SW} 480}$, respectively) than MDM + TMV0d (67 \pm 19 , $55 \pm 23,49 \pm 30,51 \pm 32 \%$ of cells for $\mathrm{TMV}_{\mathrm{SW} 620}$, TMVCaco2, $\mathrm{TMV}_{\mathrm{LoVo}}, \mathrm{TMV}_{\mathrm{SW} 480}$, respectively) and control MDM $(56 \pm 8,46 \pm 16,50 \pm 21,54 \pm 19 \%$ of cells for SW620, Caco-2, LoVo and SW480 cells, respectively). We did not observe significant changes in cytotoxicity of MDM + TMV0d or MDM + TMV036d (Fig. 9) in comparison to control MDM.

\section{Discussion}

The present data show that TMVs released by colon cancer cells influence differentiation of blood monocytes to macrophages, resulting in their mixed polarization status (M1/M2) (Fig. 10). Phenotype and biological properties of the latter depend on the time of the "first" contact of monocytes with TMVs, as well as on the TMVs origin, which is related to their cargo (proteins, lipids etc.). To compare the impact of TMVs on monocyte differentiation, four colon cancer cell lines with different growth potential were used. As a control, MVs from non-malignant HCV-29 cell line were implemented into the study. Also, in our model three different time regimens of TMVs exposition were used to mimic contact of monocytes with TMVs: i) in the peripheral blood (MDM + TMVOd), ii) in the peripheral blood and later during e.g. extravasation (MDM + TMV036d), iii) at the final stage of maturation (MDM + TMV6d) e.g. in the tumour bed.

It was previously reported that TMVs interact with human monocytes, leading to their activation [17]. The present study addressed the question whether TMVs may have an impact on monocyte differentiation and if so, what type of myeloid cells is generated as the result of this process. In the mouse model, tumour derived exosomes directed monocytes differentiation into myeloid-derived suppressor cells (MDSC), which were characterized by 

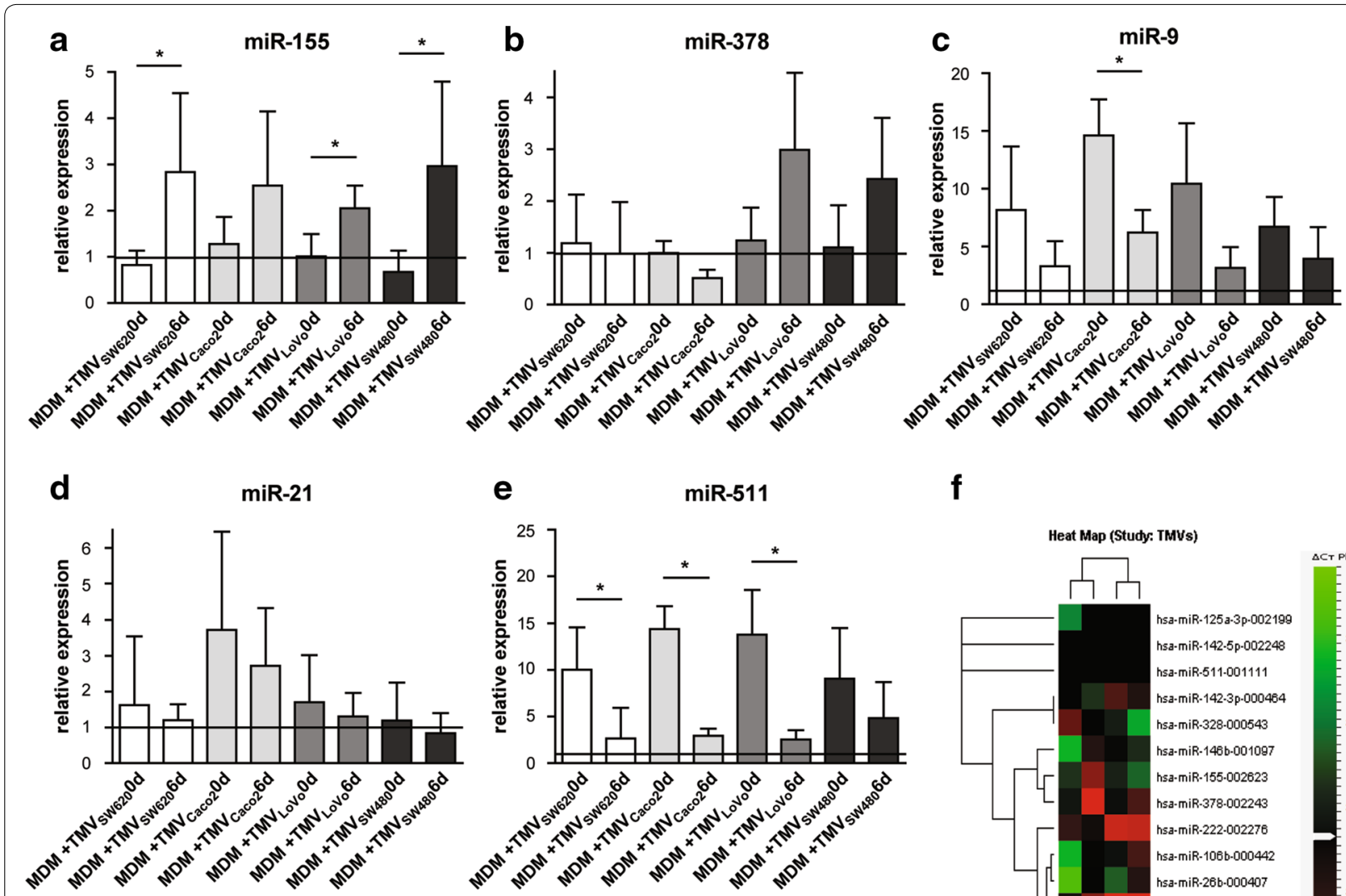

f

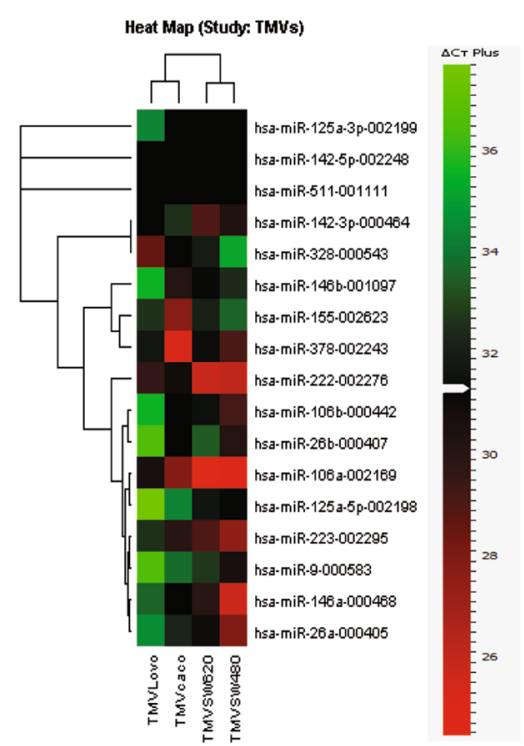

Fig. 5 Expression of selected (involved in the MDM differentiation process) microRNAs in MDM + TMV0d and MDM + TMV6d vs control MDM

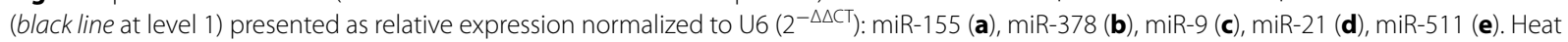
map of microRNA involved in MDM differentiation process detected in TMVs alone (f). Data from 3 independent experiments, performed in triplicates (mean $\pm \mathrm{SD}$ ) are shown. ${ }^{*} \mathrm{p}<0.05$

the expression of CD11b(+)Gr-1(+) markers [23]. Moreover, Valenti et al. showed impaired differentiation of monocytes to dendritic cells in the presence of tumour exosomes and cytokines (GM-CSF, IL-4) [24]. This study shows that TMVs alone may impact differentiation of monocytes to macrophages, however, it should be kept in mind that we used a mixed population of vesicles, not just limited to exosomes. Depending on the time of the "first" contact between monocytes/MDM and TMVs (but not "normal" MV), differences in MDM morphology, phenotype, cytokine secretion, ROI production and cytotoxicity against tumour cells in vitro were observed. We observed that TMVs present in the MDM culture induced transient cell cluster formation. The mechanism of this phenomenon is not clear, however, we suggest that this is related to hyaluronan, which is present in TMVs and MVs [25]. MDM differentiated in the presence of TMVs are bigger and more granular than control MDM. All of them showed intracellular expression of CD68 and surface expression of CD14, however, the highest CD14 expression (marker of M1 cells [26]) was observed on MDM + TMV6d.

Expression of CD206 was significantly higher on MDM + TMV0d and MDM + TMV036d than on control MDM and MDM + TMV6d. Lower expression of HLA-DR on MDM + TMV 6d was observed, but it was not significant. CD80 expression was elevated by all TMVs except for $\mathrm{TMV}_{\mathrm{SW} 620}$ (highly metastatic cell line). Expression of CD86 was significantly higher on $\mathrm{MDM}+\mathrm{TMV} 6 \mathrm{~d}$. $\mathrm{TMV}_{\mathrm{SW} 480}$ decreased expression of 

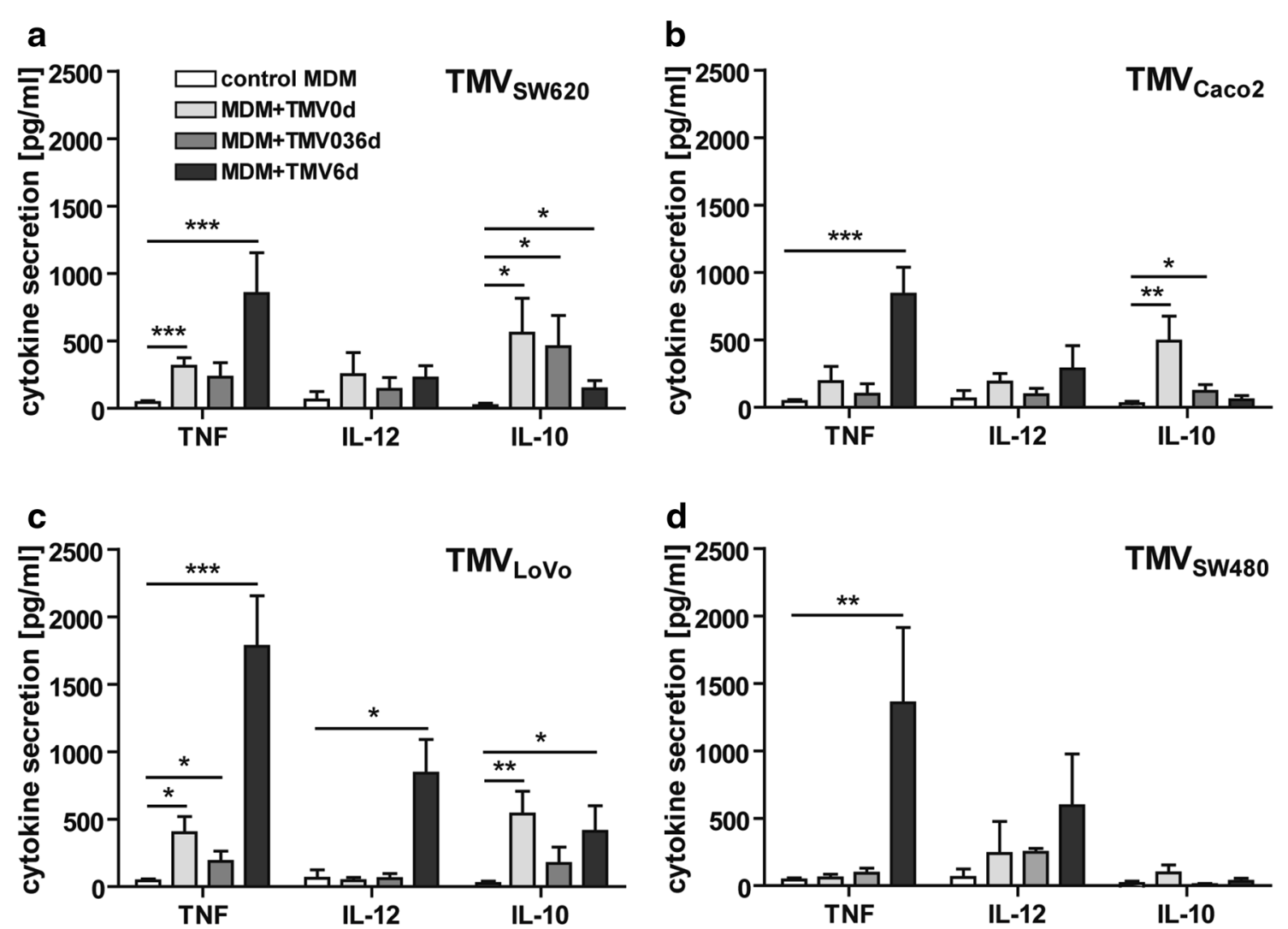

Fig. 6 Secretion of cytokines (TNF, IL-12, IL-10) by MDM differentiated with TMVs. The supernatants were collected at day 7 and cytokines level was determined by ELISA method. Cytokine secretion by MDM culture with TMV $\operatorname{SW620}_{\text {(a) }}\left(\operatorname{TMV}_{\text {Caco2 }}(\mathbf{b}), \operatorname{TMV}_{\text {Lovo }}(\mathbf{c}), \operatorname{TMV}_{\text {SW480 }}(\mathbf{d})\right.$ is presented. Data from 6 independent experiments (mean \pm SD) are shown. ${ }^{*} p<0.05,{ }^{* *} p<0.001,{ }^{* * *} p<0.0001$
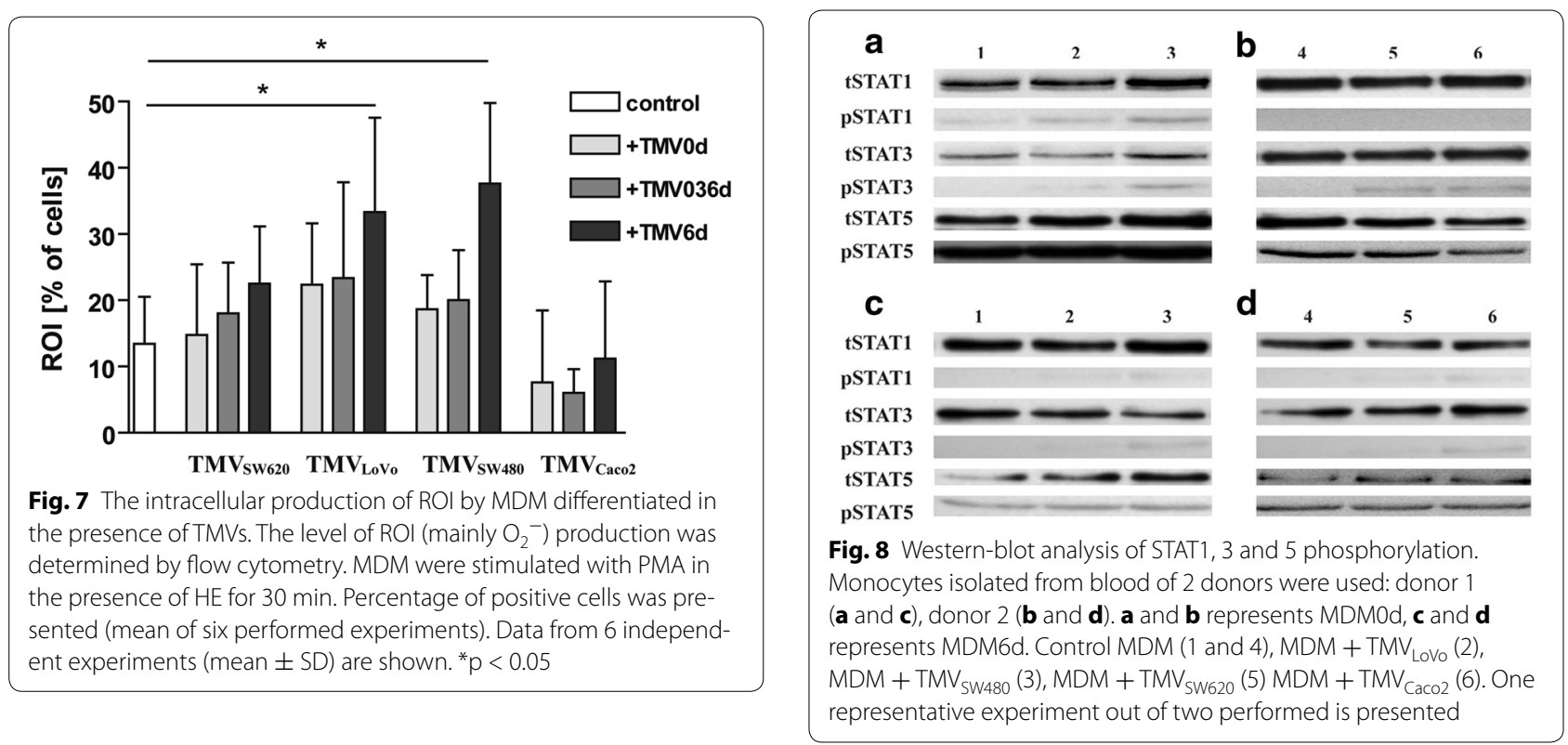
CD163 on MDM. No differences in CD115 (M-CSF R) expression were observed after contact with TMVs. We should stress out that these observation are specific for TMVs and not observed after contact with control MVs used in our study.

The phenotype of MDM + TMV6d (low HLA-DR, CD206, high CD86) combined with morphological features may indicate TAM with mixed polarization. Simultaneous phosphorylation of STAT1 and STAT3, combined with the expression of miR-155 and miR-9 supports this hypothesis. The distinct expression of HLA-DR on TAM was also observed by others [27] and usually it was attributed to hypoxia conditions in the tumour bed [28]. Based on our findings, we suggest, that the HLA-DR expression may be also influenced by the previous stimulation/contact with TMVs. In parallel, elevated expression of CD86, correlates with clinical data that most macrophages distributed along the invasive margin of colorectal carcinoma are $\mathrm{CD}^{+} 6^{+}[29,30]$. Heterogeneity of TAM phenotype was described in different tumour types [31] and at different locations of the same tumour [32, 33] e.g. in colon cancer patients, $\mathrm{CD}^{+} 0^{+} \mathrm{CD}^{+} 6^{+}$and HLA-DR ${ }^{+}$[34], as well as $\mathrm{CD}_{163}{ }^{+}, \mathrm{CD}^{\circ} 6^{+}, \mathrm{CCR} 2^{+}$cells were described [7].

The elevated expression of CD206 (M2 marker) on MDM + TMV0d and MDM + TMV036d may indicate M2 polarization. Control MDM were grown in culture medium without growth factors to develop M0 phenotype [21], however, the elevated expression of CD206 may indicate spontaneous predominance of M2 over M1 phenotype in these cells [35]. The upregulation of the mannose receptor in tumour macrophages was accompanied by increase of miR-511-3p [36], which corroborates our
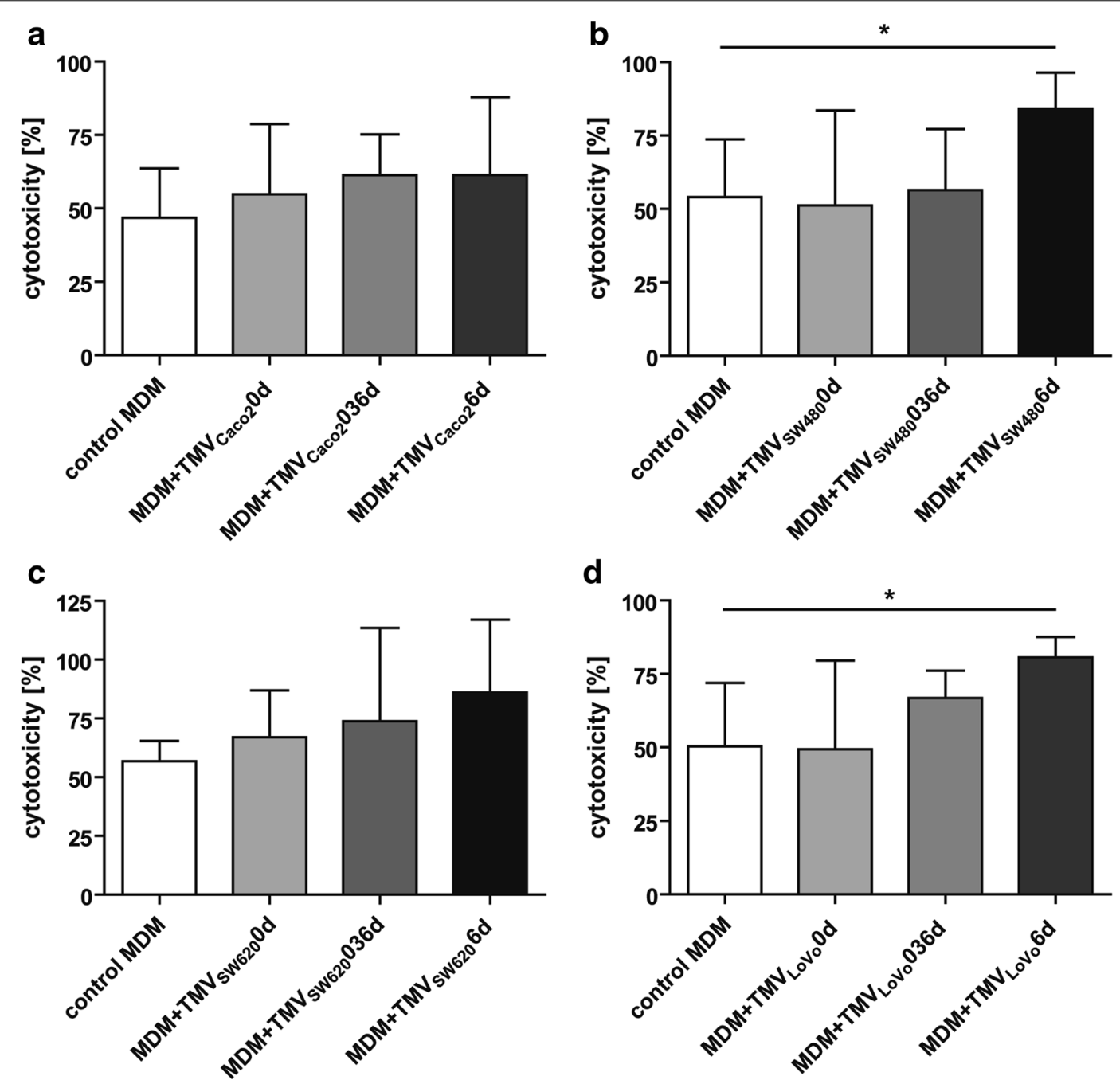

Fig. 9 Cytotoxic/cytostatic activity of MDM against tumour cells. Monocytes were differentiated in the presence of TMVs and then cocultured with appropriate tumour cells for $48 \mathrm{~h}$ (a Caco-2, b SW480, c SW620, d LoVo). Proliferation of cells was determined by MTT reduction assay. The results of five independent experiments are shown (mean \pm SD). ${ }^{*} p<0.05$ 
data (Fig. 5e). Moreover, we observed dynamic increase of CD206 expression at day 1 of culture, which correlated with dynamic changes in different miR expression during the first day of differentiation [18].

Low expression of CD115 (M-CSFR) is rather a sign of non-M2 cells, as M-CSF directed differentiation towards M2 [37]. The decrease of CD115 on macrophages was previously observed by Rovida et al. and explained by its shedding by proteases from macrophages undergoing activation [38].

Different phenotype of macrophages infiltrating tumour site may allow to predict their activation status, which subsequently may anticipate their response to tumour. In fact, TAM phenotyping may be more informative than density/number of infiltrating cells for patient prognosis [33, 37].

In this study the activation of MDM was measured by cytokine secretion, ROI production and cytotoxicity against tumour cells. Cytokine secretion by MDM and their phenotype, depended on time and frequency of the contact with TMVs and TMVs origin. The strongest secretion of TNF and IL-12 was observed when TMVs were added at the final stage of differentiation (MDM + TMV6d). In comparison, MDM + TMV0d released significantly more IL-10 than other types of MDM. MDM differentiated in the presence of
$\mathrm{TMV}_{\text {SW480 }}$ were the weakest producers of IL-10, while $\mathrm{MDM}+\mathrm{TMV}_{\mathrm{LoV}} 6 \mathrm{~d}$ and $\mathrm{MDM}+\mathrm{TMV}_{\mathrm{SW} 480} 6 \mathrm{~d}$, produced the highest amounts of TNF, which may be related to their growth potential. It is of note that MDM differentiated after a prolonged contact with TMVs (MDM + TMV036d) secreted the lowest amounts of TNF and IL-12. This is in keeping with previously described deactivation of monocytes/macrophages by tumour cells [22], which may be observed also after TMVs contact, presumably via their hyaluronan component [39].

The most potent ROI producers were MDM + TMV6d, but it seemed to be TMVs-origin dependent as TMVCaco2 did not induce production of ROI. MDM + TMV6d were more cytotoxic/cytostatic to tumour cells, most likely due to the cytotoxicity mediated by ROI and proinflammatory cytokines. Our data corroborates with the observation that TAM isolated from spheroids of human colorectal cancer expressed antitumour potential probably via secretion of proinflammatory mediators [9].

The observed differences between MDM + TMVOd and MDM + TMV6d (early and late contact) may be due to the regulation of the differentiation process via e.g. microRNA. The first scenario is, that the fate of microRNA in MDM is influenced not only by cytokines and nearby cells $[18,40]$ but also by TMVs present in the

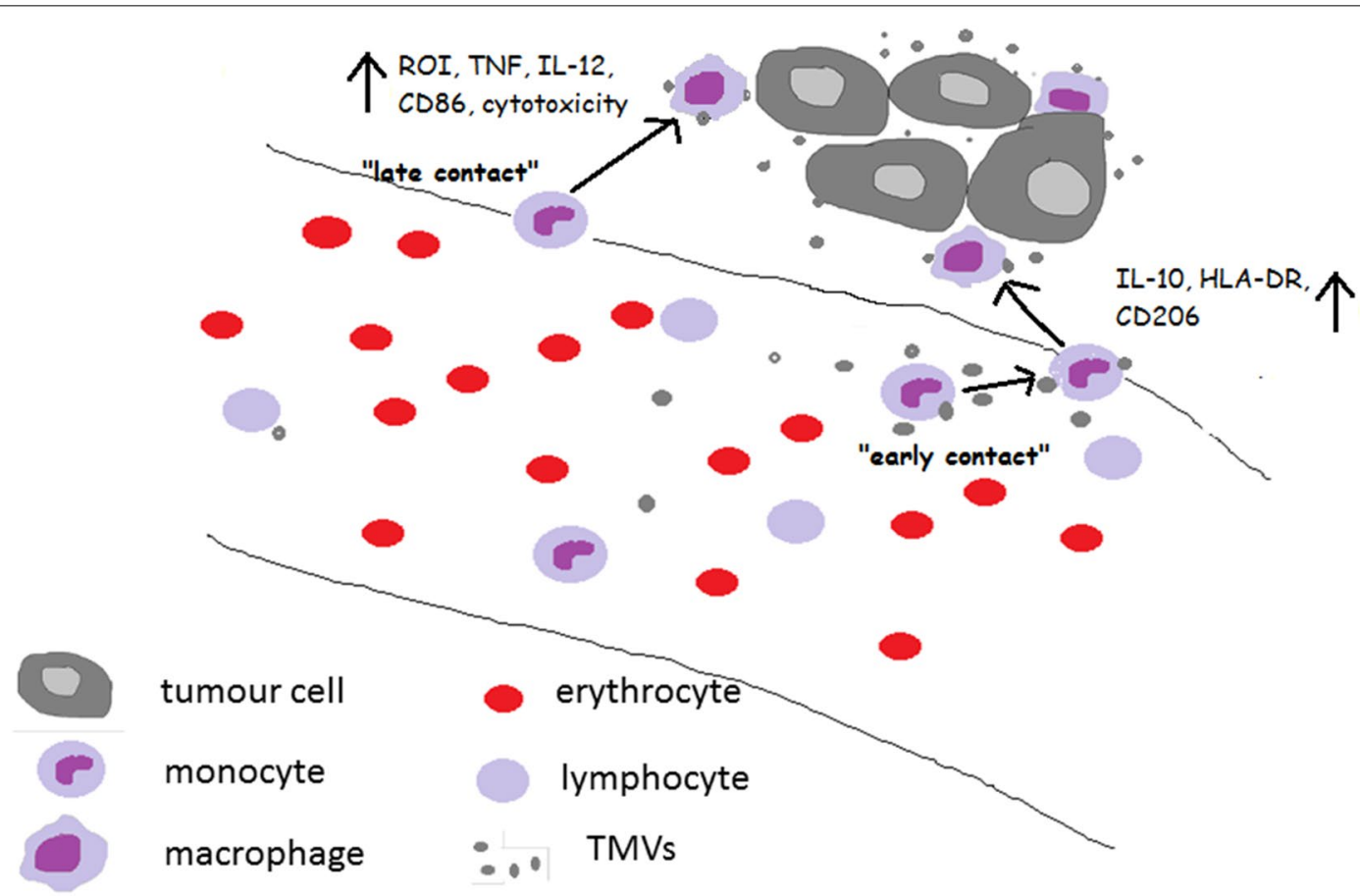

Fig. 10 Presentation of the hypothetical interactions of monocytes/macrophages with TMVs in the blood and in the tumour bed. Early contact of monocytes with TMVs resulting in M1/M2 mix polarization is schematically presented on the right. Late contact of macrophages with TMVs resulting in the induction of proinflammatory cells_left side. TMVs interactions with other immune cells as well as with tumour cells were omitted to simplify the scheme 
local environment. In keeping with this, we observed different miR expression profile in MDM + TMVOd and MDM + TMV6d. MDM after early contact with TMVs had upregulated miRs expression characteristic for M2-like cells (miR-21,-511,-9). The highest expression of these miRs was observed in the case of $\mathrm{TMV}_{\mathrm{Caco} 2}$, which induced differentiation of MDM with a lower proinflammatory capacity. MDM + TMV6d expressed higher levels of miR-155 in comparison to MDM + TMVOd and MDM control for all tested TMVs. MDM $+\mathrm{TMV}_{\mathrm{LoV}} 6 \mathrm{~d}$ and $\mathrm{MDM}+\mathrm{TMV}_{\mathrm{SW} 480} 6 \mathrm{~d}$ expressed also more miR-378. Taken together, the miR profile may suggest predominance of M2 cells after early contact and more proinflamatory cells after late contact with TMVs. Morphology of MDM + TMV6d ("fried egg"-shaped cells), and the cytokine secretion support the hypothesis of switch (at least in part of the cells) towards proinflammatory activity.

The second possibility, which complements the first one, is that miRNAs are carried by TMVs themselves. MVs were described before as safe transporters for miRNAs involved in regulation of cellular differentiation [41, 42]. TMVs used in our experiments carried miR-106a, $-146 a,-155,-222,-223,-378$ which are crucial for macrophage differentiation and activation processes [43, 44], however, quantitative assessment of this phenomenon requires further confirmation. The direct transfer of miR cannot be excluded, except for miR-511 which was not detected in TMVs.

Our and others' [45] results support the observation that TAM may have distinct properties, which do not fit perfectly the classical M1/M2 definition. We conclude that MDM differentiated in the presence of TMVs represent a mixed phenotype (M1/M2). We suggest that late contact with TMVs predisposes MDM to more proinflammatory activity. Hypothetical scenario is presented in Fig. 10. Furthermore, we suggest that biological activity of MDM is more important than their number and phenotype during tumour progression. Although, we do not have a formal proof, we suspect that removal of TMVs from blood in order to delay the first contact with monocytes, may improve macrophage activity against cancer. The idea is not new as Ichim et al. proposed a physical approach in order to remove tumour exosomes from the body fluids of the cancer patients [46]. Also, the isolation of monocytes followed by their differentiation ex vivo and "education" with TMVs may increase their anti-tumour potential. Again, the idea was already implemented, but with dendritic cells [47].

Taken together, MDM differentiated in vitro with TMVs fit the "colour wheel" classification of macrophage polarization as different "shades" of green [48], which we think, may be induced by TMVs.

\section{Conclusions}

TMVs modulated activity of monocytes and their differentiation towards macrophages. The final polarization status of macrophages was dependent on TMVs origin and the time of contact with them. We suggest, that in the case of colon cancer, late contact of MDM with TMVs induced their mix polarization with significant proinflammatory potential.

\section{Abbreviations}

TMVs: tumour-derived microvesicles; EVs: extracellular vesicles; FBS: foetal bovine serum; MDM: monocyte-derived macrophages; MFI: mean fluorescence intensity; TNF: tumour necrosis factor; IL: interleukin; TGF $\beta$ : transforming growth factor beta; PMA: phorbol 12-myristate 13-acetate; $\mathrm{ROI}$ : reactive oxygen intermediates; MDSC: myeloid-derived suppressor cells; TAM: tumour associated macrophages; RQ: relative quantity; GM-CSF: granulocyte-macrophage colony-stimulating factor; M-CSF: macrophage colony-stimulating factor; miR: microRNA.

\section{Authors' contributions}

MBK designed the study, participated in data acquisition, performed analysis and prepared the first version of manuscript, BM was responsible for the cell culture and TMVs isolation, RSz and JB participated in data analysis and manuscript preparation, MS (Marcin Surmiak) participated in data acquisition, KW performed the Western blot, MS (Maciej Siedlar) improved the manuscript with valuable comments. All authors read and approved the final manuscript.

\section{Author details}

${ }^{1}$ Department of Clinical Immunology, Institute of Peadiatrics, Medical College, Jagiellonian University, 265 Wielicka str., 30-663 Cracow, Poland. ${ }^{2}$ Division of Molecular Biology and Clinical Genetics, Department of Internal Medicine, Medical College, Jagiellonian University, Cracow, Poland.

\section{Acknowledgements}

This study was supported by the National Science Center of Poland [N N401 616040]. Publication of this study was supported by the Leading National Research Center (KNOW), Faculty of Medicine, Jagiellonian University Medical College. This article is based upon work from the COST Action BM1404 Mye-EUNITER (http://www.mye-euniter.eu, http://www.mye-euniter.eu), supported by COST (European Cooperation in Science and Technology). We wish to thank Prof. Marek Sanak and prof. Marcin Majka for the opportunity of real time microRNA analysis and Ms. Irena Ruggiero, Barbara Hajto and Mariola Ożóg for the excellent technical support.

\section{Competing interests}

The authors declare that they have no competing interests.

Received: 20 May 2015 Accepted: 18 January 2016

Published online: 02 February 2016

\section{References}

1. Weitz J, Koch M, Debus J, Hohler T, Galle PR, Buchler MW. Colorectal cancer. Lancet. 2005;14:153-65.

2. Swiderska M, Choromańska B, Dąbrowska E, Konarzewska-Duchnowska E, Choromańska K, Szczurko G, Myśliwiec P, Dadan J, Ladny JR, Zwierz K. The diagnostics of colorectal cancer. Contemp Oncol (Pozn). 2014;18:1-6.

3. Brenner H, Kloor M, Pox CP. Colorectal cancer. Lancet. 2014;383:1490-502.

4. Mantovani A, Germano G, Marchesi F, Locatelli M, Biswas SK. Cancerpromoting tumour-associated macrophages: new vistas and open questions. Eur J Immunol. 2011;41:2522-5.

5. Mantovani A, Sozzani S, Locati M, Allavena P, Sica A. Macrophage polarization: tumour-associated macrophages as a paradigm for polarized M2 mononuclear phagocytes. Trends Immunol. 2002;23:549-55. 
6. Pollard JW. Tumour-educated macrophages promote tumour progression and metastasis. Nat Rev Cancer. 2004;4:71-8.

7. Forssell J, Oberg A, Henriksson ML, Stenling R, Jung A, Palmqvist R. High macrophage infiltration along the tumour front correlates with improved survival in colon cancer. Clin Cancer Res. 2007;13:1472-9.

8. Zhou Q, Peng RQ, Wu XJ, Xia Q, Hou JH, Ding Y, Zhou QM, Zhang X, Pang $Z Z$, Wan DS, Zeng YX, Zhang XS. The density of macrophages in the invasive front is inversely correlated to liver metastasis in colon cancer. J Transl Med. 2010;8:13.

9. Ong SM, Tan SM, Beretta O, Jiang D, Yeap WH, Tai JJ, et al. Macrophages in human colorectal cancer are pro-inflammatory and prime T cells towards an anti-tumour type-1 inflammatory response. Eur J Immunol. 2012:42:89-100

10. Mantovani A, Locati M. Tumour-associated macrophages as a paradigm of macrophage plasticity, diversity, and polarization: lessons and open questions. Arterioscler Thromb Vasc Biol. 2013;33:1478-83.

11. Antonyak MA, Cerione RA. Microvesicles as mediators of intercellular communication in cancer. Methods Mol Biol. 2014;1 165:147-73.

12. Inal JM, Ansa-Addo EA, Stratton D, Kholia S, Antwi-Baffour SS, Jorfi S, Lange S. Microvesicles in health and disease. Arch Immunol Ther Exp (Warsz). 2012;60:107-21

13. Lee TH, D'Asti E, Magnus N, Al-Nedawi K, Meehan B, Rak J. Microvesicles as mediators of intercellular communication in cancer-the emerging science of cellular 'debris'. Semin Immunopathol. 2011;33:455-67.

14. Ratajczak J, Wysoczyński M, Hayek F, Janowska-Wieczorek A, Ratajczak MZ. Membrane-derived microvesicles: important and underappreciated mediators of cell-to-cell communications. Leukemia. 2006;20:1487-95.

15. Rak J. Microparticles in cancer. Semin Thromb Hemostasis. 2010;36:888-906

16. Thery C, Zitvogel L, Amigorena S. Exosomes: composition, biogenesis and function. Nat Rev Immunol. 2002;2:569-79.

17. Baj-Krzyworzeka M, Szatanek R, Weglarczyk K, Baran J, Zembala M. Tumour - derived microvesicles modulate biological activity of human monocytes. Immunol Lett. 2007;113:76-82.

18. Eigsti RL, Sudan B, Wilson ME, Graff JW. Regulation of activation-associated microRNA accumulation rates during monocyte-to-macrophage differentiation. J Biol Chem. 2014;289:28433-47.

19. Mytar B, Siedlar M, Woloszyn M, Colizzi V, Zembala M. Cross-talk between human monocytes and cancer cells during reactive oxygen intermediates generation: the essential role of hyaluronan. Int J Cancer. 2001;94:727-32.

20. Baj-Krzyworzeka M, Szatanek R, Weglarczyk K, Baran J, Urbanowicz B, Brański P, Ratajczak MZ, Zembala M. Tumour-derived microvesicles carry serveral surface determinants and mRNA of tumour cells and transfer some of these determinants to monocytes. Cancer Immunol Immunother. 2006:55:808-18

21. Mia S, Warnecke A, Zhang XM, Malmström V, Harris RA. Optimized protocol for human M2 macrophages using M-CSF and IL-4/IL-10/TGF $\beta$ yields a dominant immunosuppressive phenotype. Scand I Immunol. 2014;79:305-14

22. Mytar B, Wołoszyn M, Szatanek R, Baj-Krzyworzeka M, Siedlar M, Ruggiero I, Więckiewicz J, Zembala M. Tumour cell-induced deactivation of human monocytes. J Leukoc Biol. 2003;74:1094-101.

23. Xiang X, Poliakov A, Liu C, Liu Y, Deng ZB, Wang J, Cheng Z, Shah SV, Wang GJ, Zhang L, Grizzle WE, Mobley J, Zhang HG. Induction of myeloid-derived suppressor cells by tumour exosomes. Int J Cancer. 2009;124:2621-33.

24. Valenti R, Huber V, Filipazzi P, Pilla L, Sovena G, Villa A, Corbelli A, Fais S, Parmiani G. Rivoltini L Human tumor-released microvesicles promote the differentiation of myeloid cells with transforming growth factor-beta-mediated suppressive activity on T lymphocytes. Cancer Res. 2006;66:9290-8

25. Lenart M, Rutkowska-Zapała M, Baj-Krzyworzeka M, Szatanek R, Węglarczyk K, Smallie T, Ziegler-Heitbrock L, Zembala M, Siedlar M. Hyaluronan carried by tumor-derived microvesicles induces IL-10 production in classical (CD14 ++CD16-) monocytes via PI3 K/Akt/mTORdependent signalling pathway. Immunobiology. 2015. doi:10.1016/j. imbio.2015.06.019 (pii: S0171-2985(15)30018-8).

26. Beyer M, Mallmann MR, Xue J, Staratschek-Jox A, Vorholt D, Krebs W, Sommer D, Sander J, Mertens C, Nino-Castro A, Schmidt SV, Schultze
$J$. High-resolution transcriptome of human macrophages. PLoS One. 2012; 7:e.45466.

27. Wang B, Li Q, Qin L, Zhao S, Wang J, Chen X. Transition of tumour-associated macrophages from MHC class II(hi) to MHC class II(low) mediates tumour progression in mice. BMC Immunol. 2011;4(12):43.

28. Biswas SK, Allavena P, Mantovani A. Tumour-associated macrophages:functional diversity, clinical significance and open questions. Semin Immunopathol. 2013;35:585-600.

29. Ohtani H. Focus on TILs: prognostic significance of tumour infiltrating lymphocytes in human colorectal cancer. Cancer Immun. 2007;21(7):4

30. Ohtani H, Naito Y, Saito K, Nagura H. Expression of costimulatory molecules B7-1 and B7-2 by macrophages along invasive margin of colon cancer: a possible antitumour immunity? Lab Invest. 1997;77:231-41.

31. Squadrito ML, De Palma M. Macrophage regulation of tumour angiogenesis: implications for cancer therapy. Mol Aspects Med. 2011;32:123-45.

32. Lewis CE. PollardJW. Distinct role of macrophages in different tumour microenvironments. Cancer Res. 2006;66:605-12.

33. Van Overmeire E, Laoui D, Keirsse J, Van Ginderachter JA, Sarukhan A. Mechanisms driving macrophage diversity and specialization in distinct tumour microenvironments and parallelisms with other tissues. Front Immunol. 2014;26(5):127.

34. Kinouchi M, Miura K, Mizoi T, Ishida K, Fujibuchi W, Sasaki H, Ohnuma S, Saito K, Katayose Y, Naitoh T, Motoi F, Shiiba K, Egawa S, Shibata C, Unno M. Infiltration of CD40-positive tumour-associated macrophages indicates a favorable prognosis in colorectal cancer patients. Hepatogastroenterology. 2013;60:83-8.

35. Tedesco S, Bolego C, Toniolo A, Nassi A, Fadini GP, Locati M, Cignarella A. Phenotypic activation and pharmacological outcomes of spontaneously differentiated human monocyte-derived macrophages. Immunobiology. 2014;220:545-54 (pii: S0171-2985(14)00277-0).

36. Squadrito ML, Pucci F, Magri L, Moi D, Gilfillan GD, Ranghetti A, Casazza A, Mazzone M, Lyle R, Naldini L, De Palma M. miR-511-3p modulates genetic programs of tumour-associated macrophages. J Immunol. 2012;161:6250-7.

37. Lin EY, Pollard JW. Role of infiltrated leucocytes in tumour growth and spread. Br J Cancer. 2004;90:2053-7.

38. Rovida E, Paccagnini A, Del Rosso M, Peschon J. Dello Sbarba P.TNFalpha converting enzyme cleaves the macrophage colony-stimulating factor receptor in macrophages undergoing activation. J Immunol. 2001;166:1583-9.

39. Kuang DM, Wu Y, Chen N, Cheng J, Zhuang SM, Zheng L. Tumour-derived hyaluronan induces formation of immunosuppressive macrophages through transient early activation of monocytes. Blood. 2007;110:587-95.

40. Graff JW, Dickson AM, Clay G, McCaffrey AP, Wilson ME. Identifying functional microRNAs in macrophages with polarized phenotypes. J Biol Chem. 2012;287:21816-25.

41. Brase JC, Wuttig D, Kuner R, Sultmann H. Serum microRNAs as non-invasive biomarkers for cancer. Mol Cancer. 2010;26:306.

42. Hunter MP, Ismail N, Zhang X, Aguda BD, Lee EJ, Yu L, et al. Detection of microRNA expression in human peripheral blood microvesicles. PLoS One. 2008;3:e3694.

43. Squadrito ML, Etzrodt M, De Palma M, Pittet MJ. MicroRNA-mediated control of macrophages and its implications for cancer. Trends Immunol. 2013;34:350-9.

44. Ismail N, Wang Y, Dakhlalah D, Moldovan L, Agarwal K, Batte K, Shah P, Wisler J, Euband TD, Tridandapani S, Paulaitis E, Piper MG, Marsh CB. Macrophage microvesicles induce macrophage differentiation and miR-223 transfer. Blood. 2013;121:984-95.

45. Dumont P, Berton A, Nagy N. SandrasF, Tinton S, Demetter P, Mascart F, Allaoui A, Decaestecker C, Salmon I. Expression of galectin-3 in the tumour immune response in colon cancer. Lab Invest. 2008;88:896-906.

46. Ichim TE, Zhong Z, Kaushal S, Zheng X, Ren X, Hao X, Joyce JA, Hanley HH, Riordan NH, Koropatnick J, Bogin V, Minev BR, Min WP, Tullis RH. Exosomes as a tumour immune escape mechanism: possible therapeutic implications. J Transl Med. 2008;6:37.

47. Dai S, Wei B, Wu Z, Zhou X, Wei X, Huang H, Li G. Phase I clinical trial of autologous ascites-derived exosomes combined with GM-CSF for colorectal cancer. Mol Ther. 2008;16:782-90.

48. Mosser DM, Edwards JP. Exploring the full spectrum of macrophage activation. Nat Rev Immunol. 2008;8:958-69. 